\title{
Numerical evaluations of strain field modification induced by production flaws in loaded composite structures
}

\author{
Jan Raška ${ }^{1 *}$, Jarmil Vlach ${ }^{1}$ and Jan Horňas ${ }^{1}$ \\ ${ }^{1}$ VZLU - Czech Aerospace Research Centre, Beranových 130, 19905 Praha - Letňany, Czech \\ Republic
}

\begin{abstract}
Structural health monitoring (SHM) involves observation and analysis of a system over time using periodically sampled response measurements to monitor the initiation and propagation of a flaw. The article is focused on finite element (FE) modelling of strain field modification induced by flaws in loaded composite structures. Shape of the current production flaw - delamination - was idealised as square with a side of 1 inch. One flaw per laminate in several positions in the layup was considered. The pristine structure was modelled with one element per thickness. For delaminated zone in the centre, the twin coincident elements per thickness were adopted: first element to simulate the lay-up from bottom to delamination, second from delamination to top. The loads and the boundary conditions of the FE model were issued from the tests, based on the ASTM standards: tension test - ASTM D3039, compression after impact test ASTM D7137 and 4-point bending test - ASTM D7264. Generally, the strain modification is stronger for the delamination near the surface than for the delamination deep in the structure.
\end{abstract}

\section{Introduction}

Structural health monitoring (SHM) involves observation and analysis of a system over time using periodically sampled response measurements to monitor the initiation and propagation of a flaw. To detect the flaw initiation, many approaches, techniques, and detection systems can be used. One of the possibilities is to analyse the strain field of the loaded structure because damage or defects to loaded composite structures cause their strain field to be modified [1-4].

In this case the SHM aim is the diagnostic of the presence of damage or defects based on the measurement of the induced strain modification [2]. Specific software has been developed suitable to create such correlation.

This work is focused on modelling of strain field modification induced by flaws in loaded composite structures.

Frequent and very dangerous production flaw is a delamination, interlaminar separation of two plies $[5,6]$. The considered flaw size depends on non-destructive detection

\footnotetext{
*Corresponding author: raska@,vzlu.cz
} 
possibilities. The flaw shape was idealized as square with a side of 1 inch (25.4 mm). One flaw per laminate in several positions in the layup was considered.

\section{Material}

A non-commercial composite material used in aerospace domain was used: prepreg material composed by a carbon fibre and tough epoxy resin with content of $35 \%$. Lamina characteristics were summarised in table 1. Two lay-up configurations for 12 plies and 24 plies were defined (table 2). [8-10]

Table 1. Lamina characteristic

\begin{tabular}{|c|c|}
\hline Characteristic & Value \\
\hline $\mathrm{E}_{11}$ & $113.8 \mathrm{GPa}$ \\
\hline $\mathrm{E}_{22}=\mathrm{E}_{33}$ & $8.56 \mathrm{GPa}$ \\
\hline $\mathrm{G}_{12}=\mathrm{G}_{13}$ & $3.994 \mathrm{GPa}$ \\
\hline $\mathrm{G}_{23}$ & $2.84 \mathrm{GPa}$ \\
\hline$v_{12}=\mathrm{v}_{13}$ & 0.34 \\
\hline$v_{23}$ & 0.55 \\
\hline
\end{tabular}

Table 2. Lay-up

\begin{tabular}{|c|c|}
\hline 12 plies & {$\left[+45^{\circ} /-45^{\circ} / 0^{\circ} /+90^{\circ} / 0^{\circ} / 0^{\circ}\right] \mathrm{s}$} \\
\hline 24 plies & {$\left[+45^{\circ} /-45^{\circ} / 0^{\circ} /+90^{\circ} / 0^{\circ} / 0^{\circ} / 0^{\circ} /+90^{\circ} / 0^{\circ} / 45^{\circ} / 45^{\circ}\right] \mathrm{s}$} \\
\hline
\end{tabular}

\section{Finite element modelling}

For finite element (FE) model numerical simulation, a plate as 2D model was adopted with the current, linear, 4-node, full integrated plate elements (Nastran label QUAD4). Only linear, elastic solutions were executed. The element size and mesh quality were verified in order to FEM computing be error negligible in comparison to the flaw strain field modification.

The pristine structure was modelled with one element per thickness. For delaminated zone in the centre, the twin coincident elements per thickness were adopted: first element to simulate the lay-up from bottom to delamination, second from delamination to top (Fig. 1) [7].

\section{Numerical simulation of standard tests}

In order to compare the computed results with future experiments, the elemental loads were simulated: tension, compression, 4-point bending. The standard ASTM test was chosen. In toto, four loads and boundary conditions were issued from the tests:

- $\quad$ Tension test - ASTM D3039 
- $\quad$ Compression after impact test - ASTM D7137

- $\quad$ 4-point bending test - ASTM D7264

FE model schema

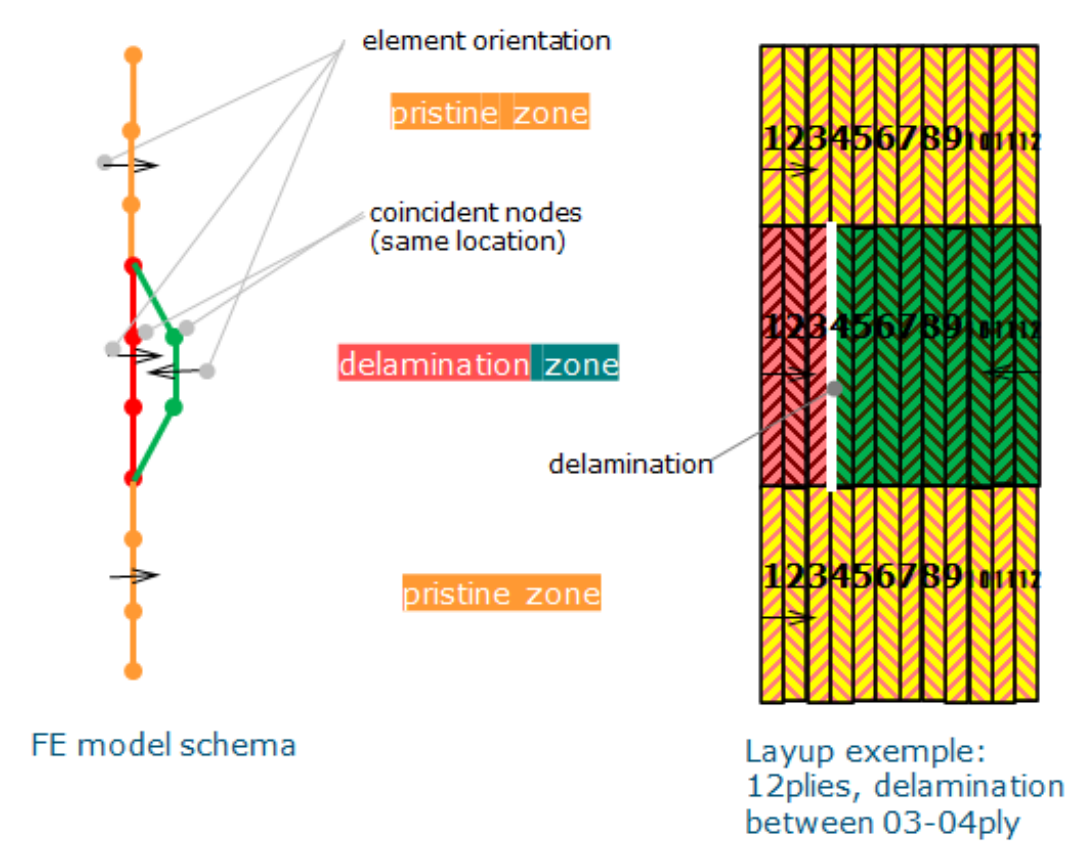

Fig. 1. Delamination FE model schema, layup example of the pristine and delamination zone.

To integrate the results of different tests, the same specimen gage section with dimensions of $100 \mathrm{~mm}$ by $150 \mathrm{~mm}$ was chosen.

The numerical simulations of various loads for the three tests were systematically executed for all delamination positions in the layup (due to the lay-up symmetry, 6 positions for 12 plies and 12 positions for 24 plies).

A typical example of the strain field modification, due to the delamination flaw, is demonstrated in Fig. 2. In this case, 12-plies laminate was loaded in 4-point bending. The field of the selected quantity - major principal strain - was compared for

1. pristine structure - Fig. $2 \mathrm{a}$

2. structure with delamination near the surface - between ply 1 and $2-$ Fig. $2 b$

3. structure with delamination in the middle - between ply 6 and $7-$ Fig. $2 c$

In case of pristine structure (Fig. 2a), the strain field is uniform in the centre area of the specimen. By contrast, the existence of the rectangular delamination flaw near the surface (Fig. 2b) is apparent by sudden strain value increase in the delaminated area, in the centre of the specimen. However, in case of delamination in the middle of composite (Fig. 2c), the strain distribution is practically identic with the pristine structure (Fig. 2a).

Per consequence, the existence of flaws is more easily detectable in case of delamination near the surface, then in case of delamination deep in the structure. 

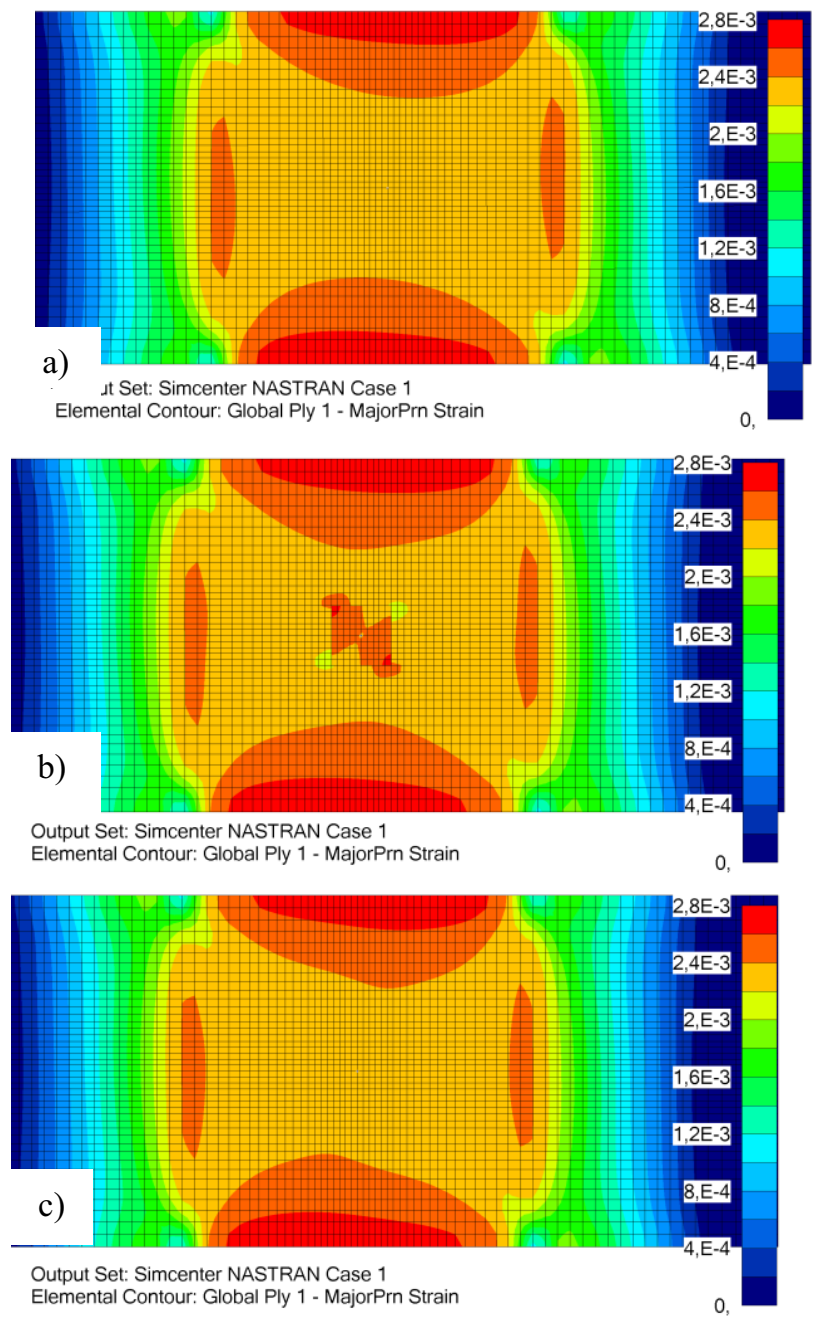

Fig. 2. Major principal strain field modification due to the delamination flaw - comparison between a) pristine structure and b) structure with delamination between plies 1-2 c) structure with delamination between plies 6-7

\section{Conclusion}

Generally, for all used standardized tests and for both laminates, the strain modification is more important for the delamination near the surface (near the top or the bottom) than for the delamination deep in the structure. Consequently, the flaw near the surface is much easily detectable than the flaw deep in the structure.

The detectability depends also on the used techniques and detection systems. Considering usual measuring equipment (digital image correlation, strain gauge), and limited load to avoid the specimen failure, the flaw is detectable:

- In case of the tension test, only for the delamination between plies 1 and 2 for both 12-plies and 24-plies laminate.

- In case of the compression test, only for delamination between plies 1-2 and 2-3 for 12-plies laminate. The delamination between plies 01-02, 02-03 and 03-04 is detectable for 24-plies laminate. 
- In case of the 4-point bending test, only the delamination between plies 1 and 2 for both 12-plies and 24-plies laminate.

\section{Acknowledgement}

This project has received funding from the European Union's Horizon 2020 research and innovation programme MODIFLAW under grant agreement No 886703.

\section{References}

1. M. Kadlec, V. Kafka, Strain Concentration during the compression of a Carbon/Epoxy Composite after impact. International Journal of Structural Integrity, 6(2), pp. 279-289. (2015) [SJR 0.48]

2. R. Růžek, M. Kadlec, K. Tserpes, E. Karachalios, Monitoring of compressive behaviour of stiffened composite panels using embedded fibre optic and strain gauge sensors, International Journal of Structural Integrity, 8(1), pp. 134-150. (2017) DOI:10.1108/IJSI-11-2015-0052

3. A. H. Baluch, O. Falcó, J. L. Jiménez, B. H. A. Tijs, C. S. Lopes, An efficient numerical approach to the prediction of laminate tolerance to Barelly Visible Impact Damage, In Composite Structures, (2019), DOI:10.1016/j.compstruct.2019.111017

4. R. Sachse, A.K. Pickett, P. Middendorf, Simulation of impact and residual strength of thick laminate composites, In Composites Part B, 195 (2020), 108070 Kadlec, M. Hron, R. - Guadagno, L.: Mechanical Properties of a Carbon Fabric-Reinforced Epoxy Composite with Carbon Nanotubes and a Flame Retardant. International Journal of Structural Integrity, Vol. 7 Iss: 5, pp.630 - 644. http://dx.doi.org/10.1108/IJSI-092015-00292020.108070

5. D. Kreculj, B. Rašau, Review of Impact Damages Modelling in Laminates Composit Aircraft Structures, In Tehnički vjesnik 20, 3 (2013), pp.485-495, ICCN 1330-3651

6. A. Sellitto, S. Saputo, F. Di Caprio, A. Riccio, A. Russo, V. Acanfora, NumericalExperimental Correlation of Impact-Induced Damages in CFRP Laminates, In Applied Sciences, 9 (2019), DOI:10.3390/app9112372

7. J. Šedek, R. Hron, M. Kadlec, Bond Joint Analysis of Thermoplastic Composite Made from Stacked Tailored Blanks. Applied Mechanics and Materials, 827 (2016), pp. 161 168, ISBN-13: 978-3-03835-531-1

8. J. Šedek, R. Hron, M. Kadlec, Evaluation of a bond joint in the carbon weave reinforced thermoplast manufactured by stacked tailored blanks, In Padevět P. and Bittnar P. (ed.), EAN 2015, 53rd Conference on Experimental Stress Analysis, 2015, Český Krumlov, Czech Republic

9. R. Růžek, K. Tserpes, E. Karachalios, Compression after impact behaviour of CFRP stiffened panels. International Journal of Structural Integrity, 2015, Vol. 6, Iss. 2., pp.176 - 193, http://dx.doi.org/10.1108/IJSI-06-2014-0030, ISSN: 1757-9864 [SJR $0.48]$.

10. M. Kadlec, R. Hron, L. Guadagno, Mechanical Properties of a Carbon FabricReinforced Epoxy Composite with Carbon Nanotubes and a Flame Retardant. International Journal of Structural Integrity, Vol. 7 Iss: 5, pp.630 - 644. http://dx.doi.org/10.1108/IJSI-09-2015-0029 